\title{
Knowledge of Teething and Prevalence of Teething Myths in Mothers of Saudi Arabia
}

\author{
Santhosh Kumar*/ Jyothi Tadakamadla** / Ali Idris***/ Idris Ali A Busaily****/ \\ Ahmed Yaqoub Ibrahim AlIbrahim*****
}

\begin{abstract}
Objectives: To assess the knowledge about teething, to evaluate the experiences of the mothers' during the teething of their youngest child and practices undertaken by them to relieve teething symptoms. Study design: A stratified cluster sampling technique was used to collect representative sample of school children of Jazan province (Saudi Arabia), who were provided with a questionnaire kit to be filled by their mothers. Results: A total of 159 mothers participated in this study. More than four-fifths and three-fourths of the study population knew that the first primary teeth erupt at 6-7 months of age and lower central incisors are the first teeth to erupt respectively. The most prevalent signs and symptoms associated with teething as reported by the mothers were desire to bite (97.5\%), fever (93\%), diarrhoea (91.1\%), increased salivation (79.9\%), loss of appetite (77.4\%) and gum irritation (71.7\%). A little more than half (55.7\%) of the mothers' gave their child a chilled object to bite and $42.1 \%$ bottle fed their baby at night to relieve teething pain. Conclusions: Many mothers had poor knowledge and misbeliefs about teething. There is a need to educate the mothers of Jazan province on the facts related to teething, specifically those related to teething pain relieving practices.
\end{abstract}

Key Words: Parents; Teething: Knowledge; Preventive practices

\section{INTRODUCTION}

$\mathrm{M}$ any childhood illnesses have been attributed to teething since centuries. Hippocrates proposed that children who have gone through painful teething period are more likely to overcome other childhood diseases. ${ }^{1}$ Many parents consider teething as an important episode of child's growth and development. ${ }^{2}$ Teething is a physiological phenomenon which involves eruption of teeth in the oral cavity from its intraosseous position in the jaw. ${ }^{3}$

\footnotetext{
*Santhosh Kumar. BDS, MDS, Population and Social Health Research Programme, Menzies Health Institute Queensland and School of Dentistry and Oral Health, Griffith University, Queensland, Australia.

Jyothi Tadakamadla** BDS, MDS, Population and Social Health Research Programme, Menzies Health Institute Queensland and School of Dentistry and Oral Health, Griffith University, Queensland, Australia.

***Ali Idris. BDS, MDS, PhD,Professor of Oral Pathology,College of Dentistry, Jazan University, Jazan KSA.

****Mr Idris Ali A Busaily,Undergraduate student,College of Dentistry ,Jazan University, Jazan KSA.

*****Mr Ahmed Yaqoub Ibrahim AlIbrahim Undergraduate student College of Dentistry, Jazan University, Jazan KSA.

Send all correspondence to:
}

Santhosh Kumar Tadakamadla

Population Social Health Research Program

Griffith Health Institute \& School of Dentistry and Oral Health

Griffith University, Gold coast

Australia

Mobile: +61415060506

E-mail: santoshkumar.tadakamadla@griffithuni.edu.au
There have been conflicting findings in the literature on the association of teething with systemic illnesses. Tighe and Roe reported many systemic symptoms occurring concurrently with teething but concluded that evidence from the literature is not enough to state that teething is the potential cause of systemic symptoms. ${ }^{4}$ However Shapira et al, examined the Gingival Crevicular Fluid (GCF) of children with teething and observed those cytokines in GCF that are related to fever, sleep disturbances, gastrointestinal disturbances and appetite disturbances. ${ }^{5}$ A wide range of symptoms have been attributed to teething which include fever, diarrhea, dermatitis, constipation, restlessness, respiratory infections, rashes and red face, increased finger sucking and decreased appetite ${ }^{6-9}$ In addition, tooth eruption can lead to intermittent localized discomfort in the area of erupting primary teeth, irritability, and excessive salivation. ${ }^{10}$ Two studies that relied on the data from objective clinical examination observed teething to be associated with systemic symptoms like drooling, diarrhea, and fever in most of the children and these systemic manifestations were more prevalent during eruption of deciduous incisors. ${ }^{11,12}$ Sood and Sood in their review have elucidated that systemic illnesses in children during teething occurs as the time frame for eruption of deciduous teeth corresponds to the reduction in maternal humoral immunity. ${ }^{13}$

Even though the evidence on the effectiveness of teething remedies is lacking, local discomfort and pain caused by teething can be managed by non-pharmacological (chewing chilled teething rings, chilled fruits or vegetables, cold wet towels, cold compression and gingival massage), pharmacological (analgesics and local anesthetics) and alternative strategies (oil based applications, herbal formulations and acupressure). ${ }^{14,15}$ 
Beliefs about the effect of teething on systemic health prevail in all the communities, so much so that; teething has been listed frequently as a cause of death in Utah records. ${ }^{16}$ It is necessary to understand the awareness of teething among parents as serious health problems that occur in children can be erroneously associated with teething. Most of the parents are often uncertain if the child's health problems are due to teething or other serious health problems. ${ }^{17}$ The present study intended to assess the knowledge about teething, evaluate experiences of the mothers during the teething of their youngest child and practices undertaken by them to relieve teething symptoms.

\section{MATERIALS AND METHOD}

The target population for the present cross-sectional survey comprised mothers of Jazan city whose children were studying in one of the public schools of Jazan, Saudi Arabia. A stratified cluster sampling technique was used; Jazan city was stratified into four regions based on the geographical directions (North, East, West and South). In each stratum, one school was randomly selected for inclusion. All the students in grade 1 were considered for inclusion. Children were provided with the questionnaires to be filled by their mothers within a week's time.

A self-administered, pre-coded, and closed ended questionnaire in Arabic was used for the present study. Target population was approached through children. All the children present on the days of the survey in the randomly selected schools were provided with a questionnaire to be carried to their mothers along with a request letter addressed to both the parents stating the purpose of the study and inviting their participation. In addition, an informed consent sheet was provided with the request letter that had to be signed or thumb imprinted by the mother. A statement was added in the request letter advising the father of the child to help the mother fill the questionnaire if she was illiterate. The filled questionnaires were collected back from the children within a week. Ethics approval for conducting this study was obtained from the ethics committee of Jazan University, Saudi Arabia.

\section{Survey instrument}

The questionnaire consisted of two parts. The first part was ascribed to collect data on mother's age, child's age, number of children, family income, occupation, and education of the mother. The second part consisted of questions regarding the knowledge about teething (eg., at what age does the tooth eruption start, which group of teeth are the first teeth to erupt, is delayed eruption of teeth associated with some systemic problems), experiences of the mothers during the teething of their youngest child (eg., which of the systemic symptoms do you think are associated with teething) and teething pain relieving practices adopted by mothers to relieve teething symptoms in their children (eg., allow the child to bite on chilled objects) which have been adopted from a previous study. ${ }^{18}$ The questionnaire was pilot tested in a convenience sample of 30 mothers visiting the dental clinics of Jazan University, based on the suggestions from the mothers few statements were reframed in Arabic for clarity without changing the meaning. As there are many signs and symptoms associated with teething in the literature, only those symptoms were included in the final questionnaire that were reported by more than $10 \%$ of the mothers in the pilot study. Consequently, symptoms like constipation, restlessness, convulsions and skin rashes were deleted from the piloted questionnaire.

\section{Statistical analysis}

SPSS, version 15.0 was used for statistical analysis. Descriptive statistics like frequencies were used to describe the knowledge, experiences and teething pain relieving practices adopted by mothers during teething of their children. Chi square test was used to assess the relationship between the child's age, mother's age, number of children, occupation, education and family income with teething related knowledge, symptoms and pain relieving practices.

\section{RESULTS}

The questionnaire was distributed to 205 mothers, of which 169 mothers returned the questionnaires with a response rate of $82.4 \%$. Ten of the returned questionnaires were excluded as they were incompletely filled and thus the final sample consisted of 159 mothers. The age of the study population ranged from 18 to 47 years. It is clear from table 1 that most of the study population $(75.9 \%)$ were aged 18-37 years and more than half of the mothers $(51.4 \%)$ were house wives. Nearly half of the subjects (42\%) have never been to school and half the respondents had annual family income in the range of 6301-12000 SR. Mothers who had one child constituted $18.5 \%$ (not presented in tables) of the total study population. More than half (62\%) of the mothers had 1-3 children.

More than four-fifths and three-fourths of the study population knew that first primary teeth erupt at 6-7 months of age and lower central incisors are the first teeth to erupt respectively while it was discouraging to observe that very few mothers $(20.9 \%)$ were aware of the fact that delayed eruption of teeth is associated with presence of systemic disease. The most prevalent signs and symptoms associated with teething as reported by their mothers were desire to bite $(97.5 \%)$, fever $(93 \%)$, diarrhoea $(91.1 \%)$, increased salivation (79.9\%), loss of appetite (77.4\%) and gum irritation (71.7\%). Nearly half the participants believed vomiting (49.4\%) and sleep disturbances $(51.1 \%)$ to be associated with teething (table 2 ). Respiratory problems $(18.2 \%)$, increased susceptibility to diseases $(23.4 \%)$, ear problems $(34.6 \%)$ and running nose $(37.1 \%)$ were observed by fewer mothers in their children during teething. On bivariate analysis, only one fourth (26.9\%) of the mothers whose youngest child was less than 6 months old knew that eruption completes by 2 years in comparison to half $(51 \%)$ of the mothers whose children were more than 2 years old. Significantly, more mothers in the youngest age group were aware of the facts that lower incisors were the first teeth to erupt and baby teeth start to erupt by 6 months when compared to the mothers in other age groups (not presented in tables). Other variables like number of children, mother's occupation, education and family income were not significantly related to teething knowledge or symptoms.

Table 3 demonstrates that slightly above half (55.7\%) of the subjects gave their child a chilled object to bite on in order to relieve pain and approximately half $(42.1 \%)$ of the mothers bottle fed their baby at night to relieve pain. In addition, over one thirds $(38.6 \%)$ and half $(50.3 \%)$ of the respondents gave systemic analgesics and applied topical analgesics respectively to relieve pain. Majority of the mothers $(84.9 \%)$ gave their children fluids to prevent dehydration during teething and more than half of the mothers (69.2\%) consulted the doctor to relieve teething symptoms in their children. There was a significant trend with more mothers informing practices to relieve tooth pain like "Biting on a chilled object" and "Consultation of 
doctor" as the age of their youngest child increased (not presented in tables). Teething pain relieving practices adopted did not differ significantly between the categories of number of children, mother's age, occupation, education and family income.

Table 1: Demographic data of the study population

\begin{tabular}{|c|c|c|}
\hline \multicolumn{2}{|c|}{ Background characteristics } & \multirow{2}{*}{$\begin{array}{c}\text { Percentage } \\
31.2\end{array}$} \\
\hline Age & $18-27$ years & \\
\hline & 28-37 years & 44.7 \\
\hline & $38-47$ years & 24.1 \\
\hline \multirow[t]{4}{*}{ Occupation } & House wife & 54.1 \\
\hline & Education sector & 35 \\
\hline & Health sector & 7.6 \\
\hline & Other & 3.2 \\
\hline \multirow[t]{5}{*}{ Education } & Never been to school & 42 \\
\hline & Primary & 27.4 \\
\hline & Secondary & 15.3 \\
\hline & Intermediate & 13.4 \\
\hline & University & 1.9 \\
\hline \multirow[t]{3}{*}{ Family income } & $<6300 \mathrm{SR}$ & 25 \\
\hline & $6301-12000 \mathrm{SR}$ & 52.2 \\
\hline & $>12000 \mathrm{SR}$ & 22.8 \\
\hline \multirow[t]{3}{*}{ Number of children } & 1-3 children & 63.1 \\
\hline & 4-6 children & 30.6 \\
\hline & $>6$ children & 6.4 \\
\hline \multirow[t]{4}{*}{ Age of the youngest child } & Less than 6 months & 16.6 \\
\hline & 6-12 months & 31.8 \\
\hline & 13-24 months & 20.4 \\
\hline & $>24$ months & 31.2 \\
\hline
\end{tabular}

Table 2: Mother's knowledge of teething and symptoms experienced by their youngest child during teething in Jazan region

\begin{tabular}{|c|c|c|c|}
\hline & Agree & Disagree & $\begin{array}{c}\text { Don't } \\
\text { knowl } \\
\text { remember }\end{array}$ \\
\hline $\begin{array}{l}\text { 'Baby teeth' start to erupt } \\
\text { around 6-7 months of age }\end{array}$ & $132(83.5)$ & $18(11.4)$ & $8(5.1)$ \\
\hline $\begin{array}{l}\text { The first teeth to appear } \\
\text { in the mouth are the lower } \\
\text { central incisors }\end{array}$ & $122(76.7)$ & $20(12.6)$ & $17(10.7)$ \\
\hline $\begin{array}{l}\text { The eruption of teeth is } \\
\text { complete at approximately } 2 \\
\text { years of age }\end{array}$ & 63(39.6) & $44(27.7)$ & $52(32.7)$ \\
\hline $\begin{array}{l}\text { Delayed eruption of teeth } \\
\text { may be an indication for } \\
\text { the presence of systemic } \\
\text { disease }\end{array}$ & $33(20.9)$ & $39(24.7)$ & $86(54.4)$ \\
\hline \multicolumn{4}{|c|}{$\begin{array}{l}\text { Signs and symptoms believed by parents, to be caused by } \\
\text { teething }\end{array}$} \\
\hline Fever & $148(93.0)$ & $10(6.4)$ & $1(0.6)$ \\
\hline Diarrhoea & $144(91.1)$ & $13(8.2)$ & $1(0.6)$ \\
\hline Sleep disturbance & $81(51.9)$ & $39(25)$ & $36(23.1)$ \\
\hline Loss of appetite & $123(77.4)$ & $16(10.1)$ & $20(12.6)$ \\
\hline Gum irritation & $114(71.7)$ & $23(14.5)$ & $22(13.8)$ \\
\hline Desire to bite & $155(97.5)$ & $1(0.6)$ & $3(1.9)$ \\
\hline Increased salivation & $127(79.9)$ & $9(5.7)$ & $23(14.5)$ \\
\hline Running nose & $59(37.1)$ & $60(37.7)$ & $40(25.2)$ \\
\hline $\begin{array}{l}\text { Respiratory system } \\
\text { problems }\end{array}$ & $29(18.2)$ & $89(56)$ & $41(25.8)$ \\
\hline Vomiting & $78(49.4)$ & $51(32.3)$ & $29(18.4)$ \\
\hline Ear problems & $55(34.6)$ & $61(38.4)$ & $43(27)$ \\
\hline $\begin{array}{l}\text { Increased susceptibility to } \\
\text { other diseases }\end{array}$ & $37(23.4)$ & $57(36.1)$ & $64(40.5)$ \\
\hline
\end{tabular}

Table 3: Preventive practices undertaken by mothers to relieve teething problems

\begin{tabular}{lccc}
\hline \multicolumn{1}{c}{ Practice to deal with teething problems } & Agree & Disagree & $\begin{array}{c}\text { Don't knowl } \\
\text { remember }\end{array}$ \\
\hline To relieve pain & & & \\
Allowed the child to bite on a chilled object & $88(55.7)$ & $54(34.2)$ & $16(10.1)$ \\
Allowed bottle feeding or nursing at night & $67(42.1)$ & $73(45.9)$ & $19(11.9)$ \\
Used systemic analgesics & $61(38.6)$ & $52(32.9)$ & $45(28.5)$ \\
Applied topical analgesics to rub the gums & $80(50.3)$ & $43(27.0)$ & $36(22.6)$ \\
Other practices & & & \\
Given the child fluids to prevent dehydration & $135(84.9)$ & $10(6.3)$ & $14(8.8)$ \\
Consulted the doctor & $110(69.2)$ & $21(13.2)$ & $28(17.6)$ \\
\hline
\end{tabular}




\section{DISCUSSION}

The present study intended to assess the knowledge and beliefs regarding teething and practices that were followed in order to relieve teething symptoms in mothers of Jazan region. Though we have initially tried to contact fathers in order to know their beliefs, the response rate was poor and that is the reason for considering only mothers in this study. As mothers are thought to be more involved in child care, they have been more frequently used as proxies than fathers; a study from Saudi Arabia observed that mothers served as better proxies for reporting the oral health related quality of life in their children than the fathers. ${ }^{19}$

Majority of the mothers were aware that the first primary teeth erupt at 6-7 months of age and lower central incisors are the first teeth to erupt, this is in accordance with a previous survey from India $^{20}$ and Jordan ${ }^{18}$ where $84 \%$ and $81.3 \%, 76.9 \%$ and $81.5 \%$ of the mothers thought that first tooth erupt by 6-7 months of age and lower central incisors are the first teeth to erupt respectively. It was discouraging to observe that very few mothers $(20.9 \%)$ were aware of the fact that delayed eruption of teeth is associated with presence of systemic disease. Systemic diseases that might cause delayed tooth eruption include Down's syndrome, Cleidocranial dysplasia, congenital hypopituitarism, congenital hypothyroidism, Gaucher's disease and osteopetrosis. ${ }^{21}$

Studies from Nigeria reported that many of the mothers, ${ }^{22,23}$ caregivers $^{24}$ and child health care workers ${ }^{25}$ thought babies can experience medical problems as a result of teething. The most prevalent systemic signs and symptoms associated with teething as reported by their mothers were desire to bite (97.5\%), fever (93\%), diarrhoea $(91.1 \%)$, increased salivation $(79.9 \%)$, loss of appetite (77.4\%) and gum irritation (71.7\%). The local irritation caused by teething might be a provoking factor in infants for their desire to bite. Further, biting relieves teething pain by overpowering the sensory receptors. ${ }^{15}$ As in our study, fever during teething has been described as one of the commonest symptom in the previous studies; however the reported prevalence of $91.1 \%$ in the current study is greater than $70 \%-80 \%$ in the previous literature. ${ }^{20,22,26}$ Diarrhoea and increased salivation were other symptoms reported by many mothers in accordance to a previous study. ${ }^{11}$ Fever and diarrhoea were commonest symptoms reported by parents ${ }^{26}$ and health care workers of Nigeria ${ }^{27}$ while a prospective study observed teething to be associated more often with increased salivation and loss of appetite. ${ }^{28}$ However, there are conflicting reports in the literature with one longitudinal study observing association between increased biting, drooling, mild temperature rise, decreased appetite for solid foods and teething. ${ }^{29}$ In contrast, another Cohort study by Wake et al, ${ }^{30}$ did not observe tooth eruption in infants to be associated with most of the teething associated systemic symptoms usually reported in the literature.

It was observed that significantly more mothers whose children were older than 2 years knew that eruption completes by 2 years than the mothers whose youngest child was less than 6 months old, the rationale explanation for this might be that the mothers whose children are currently older than 2 years would have witnessed the complete eruption process in their child. Furthermore, a majority of mothers in the youngest age group were aware of the facts that lower incisors were the first teeth to erupt and baby teeth start to erupt by 6 months when compared to the mothers in other age groups. This finding can be attributed to the fact that those mothers in the younger age group tend to have children of the teething age at the time of data collection and thus would be currently observing these milestones in their children.

Although not everyone, above half (55.7\%) of the subjects in our study gave their child a chilled object to bite on in order to relieve pain. American Academy of Paediatric Dentistry (AAPD) ${ }^{10}$ suggests that treatment of teething symptoms include oral analgesics and chilled rings for the child to bite. Although use of topical anaesthetics is discouraged by AAPD due to potential toxicity of these products in infants, half the mothers have informed of using topical anaesthetics to relive teething pain. It was astonishing to find that little less than half the mothers encouraged bottle feeding at night to relieve teething pain. It is evident from the literature that using night bottle feeding as a pacifier is associated with early childhood caries. ${ }^{31,32}$ There was a significant trend with more mothers allowing their child to bite on chilled objects and consulting the doctors as the age of their youngest child increased from 6 months to 2 years or more. Those mothers whose children are exposed to the teething problems for a longer time would have learnt about teething pain relieving practices by experience than those mothers whose children are younger.

Although a probability sampling procedure was used, the results of the current study cannot be generalised to the whole population of Jazan province due to the small sample size. Further, the data reported by mothers was subjective in nature and no objective assessments were done by the authors. It would be interesting to see if the existence of grandparents in the families affects the knowledge related to teething of mothers.

\section{CONCLUSIONS}

Many mothers had poor knowledge and misbeliefs about teething. Age of the youngest child was significantly related to mother's knowledge about the eruption dates and few of their practices to relieve teething pain. There is a need to educate the mothers of Jazan province, Saudi Arabia on the facts related to teething, specifically those related to teething pain relieving practices. 


\section{REFERENCES}

1. Ashley MP. It's only teething...a report of the myths and modern approaches to teething. Br Dent J 191: 4-8, 2001.

2. Sahin F, Camurdan AD, Camurdan MO, Olmez A, Oznurhan F, Beyazova U. Factors affecting the timing of teething in healthy Turkish infants: a prospective cohort study. Int J Paediatr Dent 18: 262-266, 2008.

3. Cunha RF, Pugliesi DM, Garcia LD, Murata SS. Systemic and local teething disturbances: prevalence in a clinic for infants. J Dent Child (Chic) 71: 24-26, 2004.

4. Tighe M, Roe MF. Does a teething child need serious illness excluding? Arch Dis Child 92: 266-268, 2007.

5. Shapira J, Berenstein-Ajzman G, Engelhard D, Cahan S, Kalickman I, Barak V. Cytokine levels in gingival crevicular fluid of erupting primary teeth correlated with systemic disturbances accompanying teething. Pediatr Dent 25: 441-448, 2003.

6. Sholapurmath SM, Anand SL, Deshpande S. General disturbances and their correlation to the eruption of primary dentition in children between 5 and 30 months age group of Belgaum city: an epidemiological study. World J Dent 2: 39-43, 2011.

7. Hatibovic-Kofman S, Ari T. Managing discomfort caused by teething. J Can Dent Assoc 79: d141, 2014.

8. Seward MH. General disturbances attributed to eruption of the human primary dentition. ASDC J Dent Child 39: 178-183, 1972.

9. Seward MH. The influence of selected factors on the number of local disturbances experienced by an infant during teething. Public Health 86: 129-136, 1972.

10. American Academy of Pediatric Dentistry. Clinical Affairs Committee--Infant Oral Health Subcommittee. Guideline on infant oral health care. Pediatr Dent 34: 148-152, 2012.

11. Peretz B, Ram D, Hermida L, Otero MM. Systemic manifestations during eruption of primary teeth in infants. $\mathrm{J}$ Dent Child (Chic) 70: 170-173, 2003.

12. Noor-Mohammed R, Basha S. Teething disturbances; prevalence of objective manifestations in children under age 4 months to 36 months. Med Oral Patol Oral Cir Bucal 17: e491-4, 2012.

13. Sood S, Sood M. Teething: myths and facts. J Clin Pediatr Dent 35: 9-13, 2010.

14. McIntyre GT, McIntyre GM. Teething troubles? Br Dent J 192: 251-255, 2002.

15. Tsang AK. Teething, teething pain and teething remedies. Int Dent SA. 12: 48-61, 2010.

16. Gibbons HL, Hebdon CK. Teething as a cause of death. A historical review. West J Med 155: 658-659, 1991.

17. Plutzer K, Keirse M. Teething: a problem for children, parents and their doctors. Medicine Today 12: 44-48, 2011.

18. Owais AI, Zawaideh F, Bataineh O. Challenging parents' myths regarding their children's teething. Int J Dent Hygiene 8: 28-34, 2010.
19. Pani SC, Badea L, Mirza S, Elbaage N. Differences in perceptions of early childhood oral health-related quality of life between fathers and mothers in Saudi Arabia. Int J Paediatr Dent 22: 244-249, 2012.

20. Kakatkar G, Nagarajappa R, Bhat N, Prasad V, Sharda A, Asawa K. Parental beliefs about children's teething in Udaipur, India: a preliminary study. Braz Oral Res 26: 151-157, 2012.

21. Holt R, Roberts G, Scully C. ABC of oral health. Oral health and disease. BMJ 320: 1652-1655, 2010.

22. Adimorah GN, Ubesie AC, Chinawa JM. Mothers' beliefs about infant teething in Enugu, South-east Nigeria: a cross sectional study. BMC Res Notes 4: 228, 2011.

23. Oziegbe EO, Folayan MO, Adekoya-Sofowora CA, Esan TA, Owotade FJ. Teething problems and parental beliefs in Nigeria. J Contemp Dent Pract 10: 75-82, 2009.

24. Agbaje MO, Ayankogbe OO, Wright KO, Adeniyi AA. The perception of caregivers attending a Nigerian teaching hospital on teething. Nig Q J Hosp Med 22: 94-98, 2012.

25. Oziegbe EO, Esan TA, Adekoya-Sofowora CA, Folayan MO. A survey of teething beliefs and related practices among child healthcare workers in Ile-Ife, Nigeria. Oral Health Prev Dent 9: 107-113, 2011.

26. Uti OG, Savage KO, Ekanem EE. Maternal beliefs about infant teething. J Community Med Prim Health Care 17: 61-64, 2005.

27. Bankole OO, Taiwo JO, Adesakin AM. Teething in infants - Knowledge and attitude of traditional birth attendants in Ibadan, Nigeria. Health 5: 1406-1411, 2013.

28. Ramos-Jorge J, Pordeus IA, Ramos-Jorge ML, Paiva SM. Prospective longitudinal study of signs and symptoms associated with primary tooth eruption. Pediatrics 128: 471-477, 2011.

29. Macknin ML, Piedmonte M, Jacobs J, Skibinski C. Symptoms associated with infant teething: a prospective study. Pediatrics 105: 747-752, 2000.

30. Wake M, Hesketh K, Lucas J. Teething and tooth eruption in Infants: A cohort study. Pediatrics 106: 1374-1379, 2000.

31. Azevedo TD, Bezerra AC, de Toledo OA. Feeding habits and severe early childhood caries in Brazilian preschool children. Pediatr Dent 27: 28-33, 2005.

32. Mohebbi SZ, Virtanen JI, Vahid-Golpayegani M, Vehkalahti MM. Feeding habits as determinants of early childhood caries in a population where prolonged breastfeeding is the norm. Community Dent Oral Epidemiol 36: 363-369, 2008 . 